\title{
Percutaneous coronary intervention of vein grafts, stenosis and thrombosis
}

\author{
Dean Strinić*, Jozica Šikić \\ University Hospital "Sveti Duh", Zagreb, Croatia
}

Introduction: Vein graft stenosis results from intimal hyperplasia, mostly within the first year, followed by atherosclerotic plaque build-up and graft remodeling in next years. As a result of these processes, patients have repeat angina symptoms and new ischemic events after coronary artery bypass graft (CABG) surgery using vein grafts (VG). Two review articles (with over 12.000 patients) noted that only about 80 percent of $V G$ semain patent five years after CABG surgery, 60 percent at 7 to 10 years, and 50 percent at 15 years.) Antiplatelets therapy (clopidogrel and aspirin) and statin use are very important as a secondary preventive interventions. Of course, avoidance of smoking and the control of blood glucose in patients with diabetes are recommended in all these patients.

Case report: 53-years old patient was admitted in February 2013 with stable angina pectoris. 1997. has had ST-segment elevation myocardial infarction (STEMI) of the inferior wall, in the same year CABG x 4 was performed. Than, after the STEMI of inferoposterior wall, percutaneous coronary intervention (PCI) of VG on the RCA was performed (January 2011). In the September 2012 coronary stent was implanted at the join of VG and RCA because of inferior STEMI. Because of $70 \%$ stenosis on the left main artery in the December 2012, elective PCI was performed.
Conclusion: The optimal management of VG stenosis that requires revascularization may involve repeat surgery or, more often $\mathrm{PCl}$ with stent implantation. Results of revascularisation are better with rePCI than reCABG. In this case, we have demonstrated that patient with $C A B G \times 4$ is sucessfully treated with $\mathrm{pPCl}$ and then elective $\mathrm{PCl}$ left main. Reoperation is associated with increased perioperative mortality, more complications than $\mathrm{PCl}$. $\mathrm{PCl}$ is preffered therapy in patients with CABG with STEMI.

KEYWORDS: percutaneous coronary intervention, stenosis, vein grafts.

\section{Literature}

1. Campeau L, Hunninghake DB, Knatterud GL, et al. Aggressive cholesterol lowering delays saphenous vein graft atherosclerosis in women, the elderly, and patients with associated risk factors. NHLBI post coronary artery bypass graft clinical trial. Post CABG Trial Investigators. Circulation. 1999;99:3241-7.

2. Knatterud GL, Rosenberg Y, Campeau L, et al. Long-term effects on clinical outcomes of aggressive lowering of low-density lipoprotein cholesterol levels and low-dose anticoagulation in the post coronary artery bypass graft trial. Post CABG Investigators. Circulation. 2000;102:157-65.

3. Chen L, ThÈroux P, LespÈrance J, Shabani F, Thibault B, De Guise P. Angiographic features of vein grafts versus ungrafted coronary arteries in patients with unstable angina and previous bypass surgery. J Am Coll Cardiol. 1996;26:1493-9.

4. Laham RJ, Carrozza JP, Berger C, Cohen DJ, Kuntz RE, Baim DS. Long-term (4- to 6-year) outcome of Palmaz-Schatz stenting: paucity of late clinical stent-related problems. J Am Coll Cardiol. 1996;28:820-6.

5. Frimerman A, Rechavia E, Eigler N, Payton MR, Makkar R, Litvack F. J Am Coll Cardiol. 1997;30:1277-83. 